\title{
Rapidly progressive crescenteric glomerulonephritis in a sandblaster with silicosis
}

\author{
D SHERSON, F JØRGENSEN \\ From the Pulmonary Clinic, Frederiksberg Hospital, Department of Nephrology, Hvidovre County Hospital, and \\ Department of Occupational Medicine, Vejle County Hospital, 7100 Vejle, Denmark
}

The suspicion that silica dust affects the kidney is at least 50 years old.' Minor abnormalities in renal function and histological changes in the kidney have been associated with exposure to silica. ${ }^{23}$ Silica has also been associated with acute renal failure which may be resistant to steroids and result in death. ${ }^{45}$ The present report describes a patient with rapidly progressive crescenteric glomerulonephritis who responded well to cytotoxic agents.

\section{Case report}

A 56 year old man was admitted in September 1984 with fever, cough, and dyspnoea. He had worked as a sandblaster for 30 years and had a 30 pack-year history of smoking cigarettes. Past medical history showed radiological pulmonary changes consistent with early stage silicosis in 1963. During the previous three years he had been treated with cimetidin because of abdominal discomfort. Laboratory studies at admission showed an increased sedimentation rate $(83 \mathrm{~mm} / \mathrm{h})$, leucocytosis $(21800 / \mathrm{mm})$, positive antinuclear factor $(+20)$, and normal serum creatinine concentration $(87 \mu \mathrm{mol} / \mathrm{l})$. Sputum culture showed normal flora and tuberculosis results were negative. Rheumatoid factor, Paul Bunell's test, cold agglutinating antibody test, mycoplasma pneumonia complement binding and C3d and C4 were negative. Chest $x$ ray examination showed multiple small infiltrates consistent with bronchopneumonia and silicosis. Under treatment with penicillin, erythromycin, and pivampicillin the temperature became normal. There was minimal improvement in dyspnoea and in the radiological abnormalities.

After stabilisation, lung function testing showed $\mathrm{FVC}=2.961(84.3 \%$ of expected $), \mathrm{FEV}_{1}=1.331$ (55.1\% of expected), and single breath diffusing capacity reduced to $51.2 \%$ of expected. A repeated

Accepted 31 October 1988 chest $x$ ray film was read as $2 / 2$ qr according to the ILO Classification of Pneumoconiosis (1980). Bronchoalveolar lavage showed a reduced total cell count $\left(6 \times 10^{3}\right.$ cells $\left./ \mathrm{ml}\right)$ with $17 \%$ lymphocytes, $80 \%$ alveolar macrophages, and 3\% neutrophiles. Transbronchial lung biopsy showed fibrosis with cyst formations as well as granuloma like nodules containing concentric fibrin consistent with silicosis. Type III collagen propeptide was raised in serum: $21.1 \mathrm{ng} / \mathrm{ml}$ (normal $=4 \cdot 9-10 \cdot 3$ ) but was not detected in nonconcentrated bronchial lavage fluid. ${ }^{6}$

One month later, the patient was transferred to a nephrological department because of acute renal insufficiency (serum creatinine concentration $340 \mu \mathrm{mol} / \mathrm{l}$ ). Three weeks later serum creatinine rose to $715 \mu \mathrm{mol} / 1$ with creatinine clearance of $9 \mathrm{ml} / \mathrm{min}$ and $24 \mathrm{~h}$ urinary protein excretion of $0.8 \mathrm{~g}$. Renal biopsy showed severe crescentric glomerulonephritis with significant oedema and cellular infiltration in the interstitium. Pathological changes were seen in 12 of the 18 glomeruli (sign Svend Larsen and Claus Brun, Institute of Pathology, Herlev Hospital). The glomerular basement membrane was intact, no haematoxylin bodies were identified. Vacuoles were seen in the proximal tubules, some of which contained erythrocyte and hyaline casts. No major disease was seen in the arteries. Immunofluorescent staining showed granular deposition of IgM and C3 along capillary loops. No IgG or IgA was seen.

Treatment was initiated with plasma exchange ( $\times 6)$, methylprednisolone $(1 \mathrm{~g}$ every other day for six days), cyclophosphamide ( $200 \mathrm{mg})$, and azathioprine $(100 \mathrm{mg}$ ). There was a good therapeutic response (see figure). Azathioprine and methylprednisolone (followed by prednisone $25 \mathrm{mg} \times 4$ daily) were rapidly stopped. Treatment with cyclophosphamide continued for 14 months. Serum creatinine concentration quickly stabilised at about $140 \mu \mathrm{mol} / \mathrm{l}$. At the last check up in 1988, it was $137 \mu \mathrm{mol} / 1$ and the creatinine clearance was $90 \mathrm{ml} / \mathrm{min}$. The National Compensation Board has accepted this case as an occupationally related disorder. 


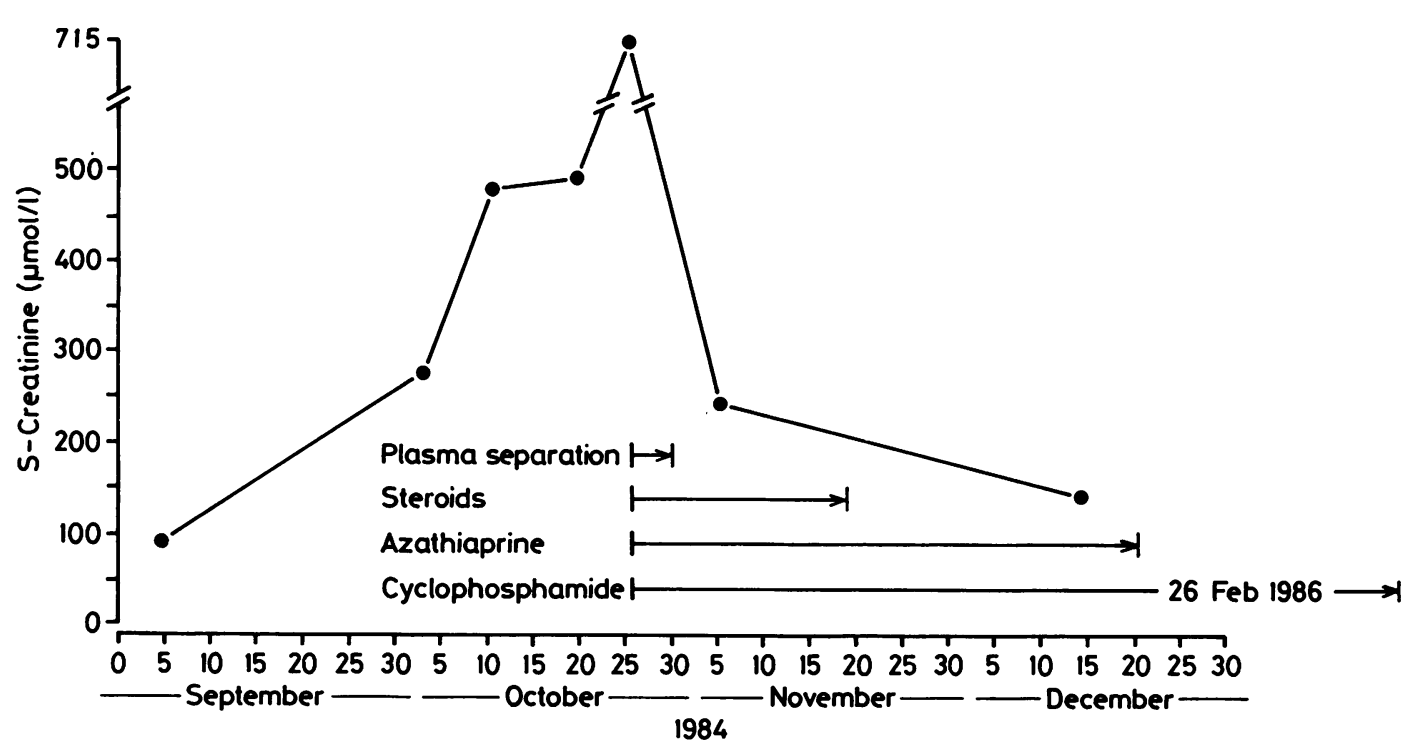

Acute renal failure and treatment response in a 56 year old sandblaster with silicosis.

\section{Discussion}

Silicotic lesions in the liver, spleen, bone marrow, and extrathoracic lymph nodes resulting from lymphohaematogenous spread have been described in 17 silicotic subjects. ${ }^{7}$ Of the 13 patients evaluated, seven had evidence of glomerulonephritis, mostly healed. In one of these cases proliferative glomerulonephritis was described. Five additional cases of proliferative glomerulonephritis in association with the inhalation of silica have also been described. ${ }^{48}$ Of the three patients with sufficient tissue also for immunofluorescense evaluation, two had granular IgM and C3 deposits on basement membrane ${ }^{4}$ (as did our patient) whereas the third had positive staining for $\mathrm{C} 3$ in the intima of the blood vessels. ${ }^{8}$ These data suggest that immune complex formation may play a part in this disorder. The aetiological importance of raised silicon levels in kidney tissue that have been described is uncertain. ${ }^{489}$

Of the five patients described in reports, two died despite steroid treatment whereas another developed chronic renal insufficiency requiring haemodialysis. ${ }^{5}$ Thus silicosis associated glomerulonephritis may be a serious disorder. Our therapeutic results suggest that aggressive immunosuppressive treatment can be helpful. Although the evidence is mainly from case histories, it seems apparent that the inhalation of silica may cause renal disease. ${ }^{10}$
We are grateful to Mrs Ulla Lund for valuable help in preparing this manuscript.

Requests for reprints to: Dr D Sherson, Departmern $\vec{\oplus}$ of Occupational Medicine, Vejle County Hospitas 7100 Vejle, Denmark.

\section{References}

1 Collis EL. A study of the mortality of coal miners, England and Wales. J Ind Hyg 1922;4:307-13.

2 Saita G, Zavagilia O. La funzionalita renale nei silicotici. Med Lav 1951;42:41-8

3 Kolev K, Doitschinor D, Todorov D. Morphologic alterations in the kidneys by silicosis. Med Lav 1970;61:205-10.

4 Giles RD, Sturgill BC, Suratt PM, Bolton WK. Massive proteinuria and acute renal failure in a patient with acute silicoproteinosis. Am J Med 1978;64:336-42.

5 Bolton WK, Suratt PM, Sturgill BC. Rapidly progressive silicon nephropathy. Am J Med 1981;71:823-8.

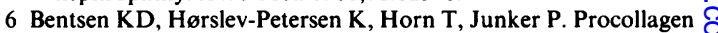
peptide in the serum of patients with rheumatoid arthritis and 3 liver disease. Ugesk Laeger 1986;148:2011-4.

7 Slavin RE, Swedo JL, Brandes D, Gonzalez-Vitale JC, Osornio- 응 Vargus A. Extrapulmonary silicosis: a clinical, morphologic and ultrastructural study. Hum Pathol 1985;16:393-412.

8 Hauglustaine D, Van Damme B, Michielsen P. Silicon nephropathy: a possible occupational hazard. Nephron $\mathrm{N}$ 1980;26:219-24.

9 Saldanha LF, Rosen VJ, Gonick HC. Silicon nephropathy. Am J N Med 1975;59:95-103.

10 Anonymous. Inhaled silica, the lung and the kidney. Lancet 1978;ii:22-3. 